\title{
A new Benders decomposition acceleration procedure for large scale multiple allocation hub location problems
}

\author{
$\underline{\text { H. Mokhtar }}^{\text {a }}$, M. Krishnamoorthy ${ }^{\mathrm{b}}$, A. T. Ernst ${ }^{\mathrm{c}}$ \\ ${ }^{a}$ Department of Mechanical and Aerospace Engineering, Monash University, Clayton VIC 3800, Australia \\ ${ }^{\mathrm{b}}$ School of IT \& Electrical Engineering, The University of Queensland QLD 4072, Australia \\ ${ }^{\mathrm{c}}$ School of Mathematical Sciences, Monash University, Clayton VIC 3800, Australia \\ Email: hamid.mokhtar@monash.edu
}

\begin{abstract}
We consider the well-known uncapacitated multiple allocation hub location problem (UMAHLP). Hub location problems are widely used to model and solve problems that arise from network telecommunications, transport networks, and delivery systems. Due to the high complexity of hub location problems, different approaches have been employed to develop efficient algorithms. We apply a modified Benders decomposition method for solving large UMAHLP instances exactly. Since the derived subproblems possess an inherent high degeneracy, the implementation of Benders method for UMAHLP usually suffers from slow convergence. We adapt an existing state-of-the-art method in the literature, and apply a novel method of accelerating this approach. This is performed with a view to addressing the slow convergence issues. Our approach improves the current best results by more appropriately choosing parameters for the accelerated Benders method.

Furthermore, as observed in the literature, the exact solution of subproblems can add an extra complexity to the Benders approach for UMAHLP. We reformulate the subproblems and solve them more efficiently using a minimum cost network flow algorithm. Our computational results show that our acceleration procedures together with our different approach to solve subproblems are computationally efficient. According to our computational results, we are able to solve larger UMAHLP instances with up to 200 nodes in less than 2 hours. On average, our approach improves computational times of around two third of tested instances by $44 \%$ over current approaches. Also it requires around $10 \%$ fewer Benders iterations in our computational experiment.
\end{abstract}

Keywords: Hub location problem, Benders decomposition methods, minimum cost network flow problem 


\section{INTRODUCTION}

Hubs are employed in several network design contexts that benefit from the economy of scale to fulfil flow requests between nodes. Hubs are used in the design of, for example, airline networks, parcel delivery networks, and telecommunications networks. Flow between nodes is routed via hubs, where each hub acts as a consolidator and forwarder. The flow between the hubs is discounted because of the large volumes that accrue from flow consolidation. In parcel/mail networks, for example, mail is collected from individual postcodes (access nodes or demand nodes), consolidated and sorted at a mail sorting centre (a hub) and transferred in larger vehicles to another mail sorting center $(h u b)$ before it is distributed to the destinations (access nodes). Hub location problems (HLP) then determine the location of the hubs and the allocations of access nodes to the hubs. Thus, as pointed out by Campbell and O'Kelly (2012), through the use of hubs, origin-destination flows/demands can be fulfilled using a smaller number of links, while delivering economies of scale. Usually it is assumed that (a) the hubs do not have capacity/flow restrictions, and (b) the hubs are fully connected. A hub location problem is single-allocation if each access-node must be allocated to exactly one hub, or multipleallocation if there is no restriction on the number of allocations. Then the uncapacitated multiple allocation hub location problem (UMAHLP) is the hub location problem in which each access-node can be allocated to multiple hubs. UMAHLP is an NP-hard combinatorial problem in general.

The research field of hub location problems commenced though the seminal works of O'Kelly $(1986,1987)$. Following this, a few variations of hub location problem were introduced and formulated by Campbell (1994, 1996). For over two decades many research works have been carried out to improve our ability to solve larger and more varied and difficult problems of hub location problems. A well-studied hub location problem in the literature is UMAHLP. For example, Mayer and Wagner (2002) enhanced the convergence of branch and bound method, and Ernst and Krishnamoorthy (1999) formulated a compact model for this class of problems. For the most recent surveys on UMAHLP see Farahani et al. (2013), Alumur and Kara (2008) and Campbell et al. (2002).

Recently, modified Benders decomposition methods have been developed, with remarkable success, for solving some classes of HLPs. Through these novel methods it is now possible to solve reasonably large instances of a certain class of HLPs to optimality. Specifically, Benders decomposition is shown to be effective for solving large instances of hub location problems (see de Camargo et al. (2008); Contreras et al. (2011)). In many cases degeneracy in the subproblems of the method could lead to slow convergence of the method. This issue was noticed and addressed by Magnanti and Wong (1981) who introduced the generation of 'pareto optimal' cuts using some 'core point'. This improvement is employed in many implementations of the Benders method, including the one by Contreras et al. (2011) for HLP with multiple allocation. Whereas Contreras et al. (2011) used this approach for generating pareto-optimal cuts, in the current paper we build on the core work of the approach by Magnanti and Wong (1981). We enhance this approach for UMAHLP by choosing better core points and generating stronger cuts.

In addition, de Camargo et al. (2008) and Contreras et al. (2011) pointed out that solving subproblems of HLP to generate cuts is computationally expensive. In this paper, we come up with a more efficient approach for solving subproblems to generate cuts by converting the subproblems to minimum cost network flow problems. Our approach has shown to be remarkably effective to solve large instances of the uncapacitated single- and multiple allocation $p$-hub median problems (see Mokhtar et al. (2017b)), and the uncapacitated 2-allocation $p$-hub median problem (see Mokhtar et al. (2017a)). Through the use of more effective Benders cuts and more efficient solution of subproblems, our method results in fewer iterations and faster running times in most cases.

\section{Problem Statement}

We are given a set of $n$ nodes $N=\{1,2, \ldots, n\}$, distances between each pair of nodes, $d_{i j}$, and a positive integer $p$ with $p \leq n$. We assume that triangle inequality for distances of nodes holds. We consider a complete digraph $G=(N, A)$, where $A=N \times N$ so that the weight of each link is the distance of its endpoints. We assume that hubs are connected through a complete graph on the set of hubs, and non-hub nodes are only connected to hubs. For every pair of nodes $(i, j), W_{i j} \geq 0$ denotes the amount of flow demand from $i$ to $j$.

In practice, the actual cost of flow between different types of nodes is computed with different cost coefficients: collection coefficient corresponds to flow from a non-hub to a hub, distribution coefficient corresponds to flow from a hub to a non-hub, transfer coefficient corresponds to flow between hubs. These are denoted by $\chi, \delta$ and $\alpha$, respectively. Usually $\alpha \leq 1, \chi \geq \alpha$ and $\delta \geq \alpha$ in practical applications.

We may assume that all flow must be routed through at most two (not necessarily distinct) hubs since using 
two hubs is always cheaper than using three or more hubs (because of the triangular inequality assumption). Therefore, any path between $i$ and $j$ must contain three links, $(i, k),(k, l)$, and $(l, j)$, where $i$ and $j$ are connected to hubs $k$ and $l$ respectively. We denote such a path by $i-k-l-j$. Let $x_{i j k l}$ be the fraction of flow request $W_{i j}$ that is sent on the $i$ - $k-l-j$ path, for all $i, j, k, l \in N$. Let binary decision variable $h_{k}=1$ if node $k$ is chosen as hub, and $h_{k}=0$ otherwise, for each $k \in N$. Then the cost of using $i-k-l-j$ path, considering the cost coefficients of different link types, is $C_{i j k l}=\chi d_{i k}+\alpha d_{k l}+\delta d_{l j}$. Furthermore, the establishment of node $k \in N$ as a hub is associated to a fixed cost $F_{k}$. An integer linear programming formulation of UMAHLP that was first introduced by Campbell (1994) is presented below:

$$
\min \sum_{k \in N} F_{k} h_{k}+\sum_{i \in N} \sum_{j \in N} \sum_{k \in N} \sum_{l \in N} C_{i j k l} W_{i j} x_{i j k l}
$$

s.t.

$$
\begin{array}{lr}
\sum_{k \in N} \sum_{l \in N} x_{i j k l}=1, & \forall i, j \in N \\
\sum_{l \in N} x_{i j k l} \leq h_{k}, & \forall i, j, k \in N \\
\sum_{k \in N} x_{i j k l} \leq h_{l}, & \forall i, j, l \in N \\
h_{k} \in\{0,1\}, x_{i j k l} \geq 0 & \forall i, j, k, l \in N .
\end{array}
$$

In the above formulation, the set of constraints (2) fulfils commodity flow requests for all pairs of nodes, and set of constraints (3)-(4) ensures flows are routed only through hubs. The objective function (1) represents total cost of hub establishments and transfer costs.

The large number of variables and constraints corresponding to the flows between pairs of nodes leads us to the idea of employing a Benders decomposition approach.

\section{BENDERS DECOMPOSITION}

The Benders decomposition method (Benders (1962)) is a partitioning algorithm which has been widely used for solving a wide range of difficult problems, including hub median problems. In the Benders decomposition method, the original problem is decomposed into a master problem and a subproblem (or a few subproblems). The master problem MP consists of integer variables and corresponding constraints, and the subproblem SP consists of the remaining variables and constraints. MP and SP are solved iteratively in a dependant manner. If SP is not feasible, then the solution of MP is not feasible for original problem, and it will be excluded from MP feasible region by a feasibility Benders cut which is generated by the dual of SP. Else, an optimality Benders cut will be added to MP to improve the feasibility of the current MP solution, until no further improvement is needed.

In order to apply Benders decomposition method to UMAHLP, the location variables $\boldsymbol{h}=\left(h_{k}\right)_{k \in N}$ are fixed to some $\hat{\boldsymbol{h}}$ in each iteration. We then obtain a linear programming subproblem in the iteration, which is the problem of optimal routing between $n^{2}$ pairs for specified hubs by $\hat{\boldsymbol{h}}$. The subproblem can be further decomposed into $n^{2}$ subproblems because we can find an optimal routing for each pair of nodes separately/independently. This decomposition results in $n^{2}$ Benders cuts, which may provide tighter cuts for the MP, and should ideally result in faster convergence. The dual of SP for any pair of nodes $(i, j) \in N^{2}$, denoted by $\mathrm{DS}_{i j}$, is as follows:

$$
\begin{array}{lll}
\mathrm{DS}_{i j}: \quad \max & f_{i j}-\sum_{k \in N} \hat{h}_{k} u_{i j k}-\sum_{l \in N} \hat{h}_{l} v_{i j l} & \\
\text { s.t. } & f_{i j}-u_{i j k}-v_{i j l} \leq C_{i j k l} W_{i j}, & \forall k, l \in N \\
& u_{i j k}, v_{i j l} \geq 0, f_{i j} \in \mathbb{R} & \forall k, l \in N .
\end{array}
$$

By an optimal solution $\left(\hat{f}_{i j}, \hat{\boldsymbol{u}}_{i j}, \hat{\boldsymbol{v}}_{i j}\right)$ of $\mathrm{DS}_{i j}$ for each $(i, j) \in N^{2}$, a Benders cut is generated. Thus, in each iteration we obtain $n^{2}$ Benders cuts:

$$
\eta_{i j} \geq \hat{f}_{i j}-\sum_{k \in N} h_{k} \hat{u}_{i j k}-\sum_{l \in N} h_{l} \hat{v}_{i j l} \quad \forall i, j \in N,
$$


where $\eta_{i j}$ is a real non-negative variable. We add a trivial constraint to MP to guarantee the feasibility of SPs for any solution $\hat{\boldsymbol{h}}$, and avoid feasibility Benders cuts for UMAHLP. With this constraint, the MP is:

$$
\begin{array}{ll}
\text { MP: } & \min \sum_{k \in N} F_{k} h_{k}+\sum_{i \in N} \sum_{j \in N} \eta_{i j} . \\
\text { s.t. } & \sum_{k \in N} h_{k} \geq 1
\end{array}
$$

(9),

$$
h_{k} \in\{0,1\}, \eta_{i j} \geq 0 \quad \forall k, i, j \in N \text {. }
$$

The optimal solution of $\mathrm{DS}_{i j}$ is not unique since SP is degenerate. The strength of Benders cuts (9) is dependent on the choice of optimal solutions of $\mathrm{DS}_{i j}$. We maximise a weighted summation of dual variables among optimal solutions of $\mathrm{DS}_{i j}$ by defining a slope for the objective function of a second LP to generate different cuts. Let $m_{i k}, m_{j l}$ for $k, l \in N$ be non-negative real parameters and $m_{0}$ be a real parameter. For $(i, j) \in N \times N$, define

$$
\begin{array}{ll}
\mathrm{DL}_{i j}: & \max m_{0} f_{i j}-\sum_{k \in N} m_{i k} u_{i j k}-\sum_{l \in N} m_{j l} v_{i j l} \\
\text { s.t. } & f_{i j}-\sum_{k \in N} \hat{z}_{i k} u_{i j k}-\sum_{l \in N} \hat{z}_{j l} v_{i j l}=\hat{\delta}_{i j} \\
& (7)-(8),
\end{array}
$$

where $\hat{\delta}_{i j}$ is the optimal value of $\mathrm{DS}_{i j}$.

The strength of our generated Benders cuts is directly related to the slope of the objective function of the above SPs. When $\left(h_{k}^{\prime}\right)_{k \in N}$ is an interior point of the convex hull of MP (called a 'core point'), and $m_{0}=1$, we obtain an acceleration of the Benders method proposed by Magnanti and Wong (1981), which is shown to generate 'pareto optimal' cuts. The cuts that are generated by their method, however, might not be the strongest cuts in general. We observed that in most cases (across a few test implementations we ran) a modification of their method - in which the objective function is minimised - results in stronger cuts, fewer number of branch and bound iterations, and faster convergence. So pareto optimality is not sufficient to measure the strength of Benders cuts.

Here, we set $\boldsymbol{m}_{i j}=\left(m_{i 1}, \ldots, m_{i n}, m_{j 1}, \ldots, m_{j n}\right)$ for $\mathrm{DL}_{i j}$ which may not be equivalent to a core point, but may result in stronger cuts for UMAHLP in general:

$$
\begin{cases}m_{i k}=\Gamma_{i} /(n-p) \text { and } m_{j k}=\Gamma_{j} /(n-p) & \text { if } \hat{h}_{k}=0 \\ m_{i k}=m_{j k}=1, & \text { if } \hat{h}_{k}=1\end{cases}
$$

for some $\Gamma_{i}, \Gamma_{j}>0$. By this combination, we control the number of non-zero coefficients of location variables $h_{k}$ in Benders cuts which are associated to $i-j$ paths through non-hubs shorter than $i-\hat{k}-\hat{l}-j$, where $i-\hat{k}-\hat{l}-j$ is the shortest path through hubs specified by $\hat{\boldsymbol{h}}$. We show in next section that, on average, our approach for such choice of $\boldsymbol{m}_{i j}$ substantially reduces the number of iterations and the computational time.

Another issue we address in this paper is the computationally expensive generation of Benders cuts. By exploiting the structure of SPs, we reformulate SPs as minimum cost network flow problems on an auxiliary network with $2 n+2$ nodes and $n^{2}+2 n$ arcs. Let $S=\Gamma_{i}+\Gamma_{j}-m_{0}$, and $H^{0}=\left\{k \in N: \hat{h}_{k}=0\right\}$. Then the dual of $\mathrm{DL}_{i j}$ is equivalent to the following minimum cost network flow problem:

$$
\min \sum_{k=1}^{n} \chi d_{i k} W_{i j} r_{s_{i} k}+\sum_{k=1}^{n} \sum_{l=n+1}^{2 n} \alpha d_{k l} W_{i j} r_{k l}+\sum_{l=n+1}^{2 n} \delta d_{(l-n) j} W_{i j} r_{l t_{j}}
$$

s.t. 
H. Mokhtar, et al., A new Benders decomposition acceleration for large scale HLP

$$
\begin{array}{rlr}
\sum_{k \in N} r_{s_{i} k} & =\Gamma_{i}+\Gamma_{j} & \\
\sum_{l=n+1}^{2 n} r_{l k}-r_{s_{i} k} & & \\
r_{l t_{j}}-\sum_{k \in N} r_{k l} & & \\
\quad-\sum_{l=n+1}^{2 n} r_{l t_{j}} & & \\
r_{s_{i} k} & & \\
r_{s_{i} \hat{k}} & \leq m_{i k} & \\
r_{(l+n) t_{j}} & \leq m_{i \hat{k}}+S & \\
r_{(\hat{l}+n) t_{j}} & \leq m_{j l} & \\
r_{s_{i} k}, r_{l t_{j}}, r_{k l} \geq 0 & \leq m_{j \hat{l}}+S & \\
& &
\end{array}
$$

Then using an optimal solution of the above problem, we can obtain a feasible and optimal solution for $\mathrm{DL}_{i j}$ efficiently. Therefore, using an efficient algorithm to solve the above problem, the Benders cuts can be generated more efficiently.

\section{Computational Results}

We compare the computational results of our modified Benders method and existing Benders approaches for UMAHLP in the literature. Table 1 presents the computational results on instances with $n$ nodes and transfer coefficient $\alpha$ in the Australia Post data sets, which was introduced to the literature by Ernst and Krishnamoorthy (1996). Our algorithms were coded in C/C++ using CPLEX 12.7, and our computational experiments were performed on a PC with 8 cores of $3.6 \mathrm{GHz}$ speed and 32G RAM with time limit of 2 hours. We excluded computational results by branch and bound by CPLEX from our table since this method is not able to load problems with $n \geq 60$ to our machine.

Following the computational settings in Contreras et al. (2011), we set collection and distribution factors $\chi=\delta=1$, and transfer factor $\alpha \in\{0.2,0.5,0.8\}$ to compare computational results on similar problems with existing benchmark results. Also we used fixed cost data sets ('loose' version) in the AP data sets, and generalised a method by Ernst and Krishnamoorthy (1996) of generating smaller size instances to produce fixed cost data for larger instances. By introducing a factor, we can vary the relative magnitude of the fixed costs with respect to the transfer costs. This factor eventually affects the number of located hubs for a problem. In other words, we experiment solving problems in which the transfer cost for $(i, j)$ through hubs $k$ and $l$ is changed to $C_{i j k l} / \mathrm{TCF}$ for some TCF $\in\{111,190,500\}$. Contreras et al. (2011) also used factors to control the balance of fixed costs and transfer costs, which unfortunately we are unable to reproduce for the AP data set. However, we chose TCF so that the number of located hubs for the same problems are almost the same (see Table 1). In Table 1, 'Hubs', 'B-itr', 'time', and 't' respectively indicate the number of hubs, the number of Benders iterations, the computational time ( $\mathrm{sec}$ ), and that the corresponding method was not able to solve within the time limit. The computational results of existing benchmark results in Table 1 are those that are reported by Contreras et al. (2011). We point out that the comparison in Table 1 is only between Benders approaches. Contreras et al. (2011) further used a heuristic algorithm and an elimination test to improve their computational results. Our objective here is merely to test the efficiency of our new approaches for Benders acceleration and solution of the subproblems for UMAHLP.

In our approach we choose $\Gamma_{i}=1.2, \Gamma_{j}=0.8$, and $m_{0}=1$ in (15). Our chosen core-point is different from the core-point chosen by Contreras et al. (2011), where they set $h_{k}=0.1$ for $k \in N$. Furthermore, they did not solve SPs to optimality since they observed that it was computationally expensive and hence they used approximate solutions for SPs. However we modelled SPs as minimum cost network flow problems and efficiently solved them by network simplex method to optimality. According to Table 1, our acceleration of Benders decomposition method is very efficient for solving UMAHLP, and our choice of core points improves the convergence rate. Our method outperforms results by de Camargo et al. (2008) in all tested instances, and also the results by Contreras et al. (2011) for around two thirds of the instances in terms of computational time. Additionally, our approach requires fewer Benders iterations in comparison with the approach by Contreras 
H. Mokhtar, et al., A new Benders decomposition acceleration for large scale HLP

Table 1. Computational results of Benders approaches for UMAHLP on Australia Post data sets

\begin{tabular}{|c|c|c|c|c|c|c|c|c|c|c|}
\hline \multirow[b]{2}{*}{$n$} & \multirow[b]{2}{*}{$\alpha$} & \multirow[b]{2}{*}{ TCF } & \multirow[b]{2}{*}{ Hubs } & \multirow{2}{*}{\begin{tabular}{|r|} 
de Camargo et al. (2008) \\
time
\end{tabular}} & \multicolumn{2}{|c|}{ Contreras et al. (2011) } & \multicolumn{4}{|c|}{ Accelerated Benders method } \\
\hline & & & & & B-itr & time & TCF & Hubs & B-itr & time \\
\hline 25 & 0.2 & $\begin{array}{r}2 \\
5 \\
10\end{array}$ & $\begin{array}{l}2 \\
5 \\
8\end{array}$ & $\begin{array}{r}0.24 \\
4.01 \\
73.00\end{array}$ & $\begin{array}{r}5 \\
11 \\
17\end{array}$ & $\begin{array}{l}0.11 \\
0.77 \\
1.97\end{array}$ & $\begin{array}{l}500 \\
190 \\
111\end{array}$ & $\begin{array}{l}1 \\
5 \\
7\end{array}$ & $\begin{array}{r}4 \\
13 \\
9\end{array}$ & $\begin{array}{l}0.04 \\
0.24 \\
0.14\end{array}$ \\
\hline & 0.5 & $\begin{array}{r}2 \\
5 \\
10\end{array}$ & $\begin{array}{l}2 \\
4 \\
6\end{array}$ & $\begin{array}{r}0.20 \\
1.76 \\
10.78\end{array}$ & $\begin{array}{r}5 \\
15 \\
13\end{array}$ & $\begin{array}{l}0.13 \\
1.03 \\
1.18\end{array}$ & $\begin{array}{l}500 \\
190 \\
111\end{array}$ & $\begin{array}{l}1 \\
5 \\
6\end{array}$ & $\begin{array}{r}3 \\
12 \\
10\end{array}$ & $\begin{array}{l}0.03 \\
0.12 \\
0.15\end{array}$ \\
\hline & 0.8 & $\begin{array}{r}2 \\
5 \\
10\end{array}$ & $\begin{array}{l}2 \\
2 \\
5\end{array}$ & $\begin{array}{l}0.19 \\
0.56 \\
2.54\end{array}$ & $\begin{array}{r}5 \\
7 \\
10\end{array}$ & $\begin{array}{l}0.08 \\
0.18 \\
0.55\end{array}$ & $\begin{array}{l}500 \\
190 \\
111\end{array}$ & $\begin{array}{l}1 \\
2 \\
5\end{array}$ & $\begin{array}{r}3 \\
6 \\
10\end{array}$ & $\begin{array}{l}0.03 \\
0.08 \\
0.12\end{array}$ \\
\hline 50 & 0.2 & $\begin{array}{r}2 \\
5 \\
10\end{array}$ & $\begin{array}{l}2 \\
4 \\
7\end{array}$ & $\begin{array}{r}4.18 \\
20.38 \\
624.41\end{array}$ & $\begin{array}{r}8 \\
11 \\
20\end{array}$ & $\begin{array}{r}1.11 \\
2.58 \\
15.13\end{array}$ & $\begin{array}{l}500 \\
190 \\
111\end{array}$ & $\begin{array}{l}2 \\
4 \\
6\end{array}$ & $\begin{array}{l}8 \\
9 \\
9\end{array}$ & $\begin{array}{l}1.06 \\
1.64 \\
1.70\end{array}$ \\
\hline & 0.5 & $\begin{array}{r}2 \\
5 \\
10\end{array}$ & $\begin{array}{l}2 \\
3 \\
6\end{array}$ & $\begin{array}{r}2.65 \\
12.04 \\
67.16\end{array}$ & $\begin{array}{r}6 \\
13 \\
16\end{array}$ & $\begin{array}{l}0.82 \\
3.12 \\
6.95\end{array}$ & $\begin{array}{l}500 \\
190 \\
111\end{array}$ & $\begin{array}{l}2 \\
3 \\
6\end{array}$ & $\begin{array}{r}7 \\
13 \\
9\end{array}$ & $\begin{array}{l}0.90 \\
2.40 \\
1.77\end{array}$ \\
\hline & 0.8 & $\begin{array}{r}2 \\
5 \\
10\end{array}$ & $\begin{array}{l}2 \\
2 \\
5\end{array}$ & $\begin{array}{r}2.33 \\
5.35 \\
35.04\end{array}$ & $\begin{array}{r}6 \\
8 \\
17\end{array}$ & $\begin{array}{l}0.08 \\
1.22 \\
6.73\end{array}$ & $\begin{array}{l}500 \\
190 \\
111\end{array}$ & $\begin{array}{l}2 \\
3 \\
4\end{array}$ & $\begin{array}{r}7 \\
10 \\
9\end{array}$ & $\begin{array}{l}0.58 \\
1.12 \\
1.54\end{array}$ \\
\hline 75 & 0.2 & $\begin{array}{r}2 \\
5 \\
10\end{array}$ & $\begin{array}{l}2 \\
4 \\
7\end{array}$ & $\begin{array}{r}27.43 \\
73.94 \\
2208.01\end{array}$ & $\begin{array}{r}9 \\
10 \\
16\end{array}$ & $\begin{array}{r}5.20 \\
7.00 \\
16.23\end{array}$ & $\begin{array}{l}500 \\
190 \\
111\end{array}$ & $\begin{array}{l}2 \\
4 \\
6\end{array}$ & $\begin{array}{r}7 \\
11 \\
12\end{array}$ & $\begin{array}{r}4.22 \\
10.88 \\
31.76\end{array}$ \\
\hline & 0.5 & $\begin{array}{r}2 \\
5 \\
10\end{array}$ & $\begin{array}{l}2 \\
4 \\
7\end{array}$ & $\begin{array}{r}21.40 \\
53.98 \\
129.12\end{array}$ & $\begin{array}{r}8 \\
12 \\
11\end{array}$ & $\begin{array}{l}4.47 \\
6.99 \\
7.15\end{array}$ & $\begin{array}{l}500 \\
190 \\
111\end{array}$ & $\begin{array}{l}2 \\
2 \\
4\end{array}$ & $\begin{array}{l}5 \\
6 \\
9\end{array}$ & $\begin{array}{l}2.40 \\
2.78 \\
8.62\end{array}$ \\
\hline & 0.8 & $\begin{array}{r}2 \\
5 \\
10\end{array}$ & $\begin{array}{l}2 \\
2 \\
5\end{array}$ & $\begin{array}{l}17.02 \\
50.29 \\
77.54\end{array}$ & $\begin{array}{r}9 \\
12 \\
13\end{array}$ & $\begin{array}{l}4.50 \\
6.08 \\
7.19\end{array}$ & $\begin{array}{l}500 \\
190 \\
111\end{array}$ & $\begin{array}{l}2 \\
2 \\
4\end{array}$ & $\begin{array}{l}6 \\
9 \\
9\end{array}$ & $\begin{array}{l}2.94 \\
4.99 \\
6.70\end{array}$ \\
\hline 100 & 0.2 & $\begin{array}{r}2 \\
5 \\
10\end{array}$ & $\begin{array}{l}2 \\
4 \\
7\end{array}$ & $\begin{array}{r}210.72 \\
1364.60 \\
\mathrm{t}\end{array}$ & $\begin{array}{r}7 \\
23 \\
23\end{array}$ & $\begin{array}{r}14.64 \\
69.15 \\
170.00\end{array}$ & $\begin{array}{l}500 \\
190 \\
111\end{array}$ & $\begin{array}{l}2 \\
4 \\
7\end{array}$ & $\begin{array}{r}8 \\
15 \\
18\end{array}$ & $\begin{array}{r}15.90 \\
86.47 \\
117.90\end{array}$ \\
\hline & 0.5 & $\begin{array}{r}2 \\
5 \\
10\end{array}$ & $\begin{array}{l}2 \\
3 \\
6\end{array}$ & $\begin{array}{r}165.75 \\
787.01 \\
4586.82\end{array}$ & $\begin{array}{r}7 \\
20 \\
24\end{array}$ & $\begin{array}{r}13.66 \\
38.85 \\
113.32\end{array}$ & $\begin{array}{l}500 \\
190 \\
111\end{array}$ & $\begin{array}{l}2 \\
4 \\
5\end{array}$ & $\begin{array}{r}6 \\
16 \\
14\end{array}$ & $\begin{array}{r}9.56 \\
54.09 \\
55.86\end{array}$ \\
\hline & 0.8 & $\begin{array}{r}2 \\
5 \\
10\end{array}$ & $\begin{array}{l}2 \\
2 \\
4\end{array}$ & $\begin{array}{r}126.38 \\
259.70 \\
1198.83\end{array}$ & $\begin{array}{r}6 \\
11 \\
20\end{array}$ & $\begin{array}{l}12.91 \\
17.54 \\
38.38\end{array}$ & $\begin{array}{l}500 \\
190 \\
111\end{array}$ & $\begin{array}{l}2 \\
3 \\
4\end{array}$ & $\begin{array}{r}6 \\
8 \\
12\end{array}$ & $\begin{array}{r}8.65 \\
11.17 \\
23.87\end{array}$ \\
\hline 125 & 0.2 & $\begin{array}{r}2 \\
5 \\
10\end{array}$ & $\begin{array}{l}2 \\
4 \\
7\end{array}$ & $\begin{array}{r}747.44 \\
2406.95 \\
\mathrm{t}\end{array}$ & $\begin{array}{l}10 \\
12 \\
25\end{array}$ & $\begin{array}{r}47.20 \\
52.92 \\
170.82\end{array}$ & $\begin{array}{l}500 \\
190 \\
111\end{array}$ & $\begin{array}{l}2 \\
4 \\
6\end{array}$ & $\begin{array}{r}9 \\
16 \\
16\end{array}$ & $\begin{array}{r}42.37 \\
196.47 \\
416.41\end{array}$ \\
\hline & 0.5 & $\begin{array}{r}2 \\
5 \\
10\end{array}$ & $\begin{array}{l}2 \\
4 \\
5\end{array}$ & $\begin{array}{r}503.83 \\
2150.63 \\
\mathrm{t}\end{array}$ & $\begin{array}{r}6 \\
16 \\
25\end{array}$ & $\begin{array}{r}36.63 \\
53.26 \\
137.54\end{array}$ & $\begin{array}{l}500 \\
190 \\
111\end{array}$ & $\begin{array}{l}2 \\
3 \\
4\end{array}$ & $\begin{array}{r}6 \\
13 \\
19\end{array}$ & $\begin{array}{r}25.83 \\
144.24 \\
449.83\end{array}$ \\
\hline & 0.8 & $\begin{array}{r}2 \\
5 \\
10\end{array}$ & $\begin{array}{l}2 \\
3 \\
4\end{array}$ & $\begin{array}{r}459.49 \\
1061.16 \\
\mathrm{t}\end{array}$ & $\begin{array}{r}6 \\
9 \\
13\end{array}$ & $\begin{array}{l}35.70 \\
38.06 \\
45.66\end{array}$ & $\begin{array}{l}500 \\
190 \\
111\end{array}$ & $\begin{array}{l}2 \\
2 \\
4\end{array}$ & $\begin{array}{r}8 \\
13 \\
18\end{array}$ & $\begin{array}{r}22.02 \\
56.12 \\
128.48\end{array}$ \\
\hline 150 & 0.2 & $\begin{array}{r}2 \\
5 \\
10\end{array}$ & $\begin{array}{l}2 \\
4 \\
7\end{array}$ & $\begin{array}{r}2360.82 \\
\mathrm{t} \\
2360.82\end{array}$ & $\begin{array}{l}12 \\
16 \\
25\end{array}$ & $\begin{array}{l}138.66 \\
143.40 \\
455.93\end{array}$ & $\begin{array}{l}500 \\
190 \\
111\end{array}$ & $\begin{array}{l}2 \\
4 \\
6\end{array}$ & $\begin{array}{r}9 \\
11 \\
18\end{array}$ & $\begin{array}{r}151.66 \\
309.81 \\
1164.53\end{array}$ \\
\hline & 0.5 & $\begin{array}{r}2 \\
5 \\
10\end{array}$ & $\begin{array}{l}2 \\
4 \\
6\end{array}$ & $\begin{array}{r}1814.04 \\
\mathrm{t} \\
\mathrm{t}\end{array}$ & $\begin{array}{r}6 \\
22 \\
20\end{array}$ & $\begin{array}{r}91.57 \\
155.32 \\
202.96\end{array}$ & $\begin{array}{l}500 \\
190 \\
111\end{array}$ & $\begin{array}{l}2 \\
3 \\
6\end{array}$ & $\begin{array}{r}9 \\
13 \\
18\end{array}$ & $\begin{array}{r}78.91 \\
364.93 \\
856.72\end{array}$ \\
\hline & 0.8 & $\begin{array}{r}2 \\
5 \\
10\end{array}$ & $\begin{array}{l}2 \\
4 \\
6\end{array}$ & $\begin{array}{l}1278.42 \\
3816.60 \\
6638.50\end{array}$ & $\begin{array}{r}5 \\
15 \\
16\end{array}$ & $\begin{array}{r}82.82 \\
107.40 \\
123.39\end{array}$ & $\begin{array}{l}500 \\
190 \\
111\end{array}$ & $\begin{array}{l}2 \\
3 \\
4\end{array}$ & $\begin{array}{l}10 \\
11 \\
18\end{array}$ & $\begin{array}{r}73.18 \\
89.02 \\
309.62\end{array}$ \\
\hline 175 & 0.2 & $\begin{array}{r}2 \\
5 \\
10\end{array}$ & $\begin{array}{l}2 \\
2 \\
5\end{array}$ & $\begin{array}{r}2062.87 \\
\mathrm{t} \\
\mathrm{t}\end{array}$ & $\begin{array}{r}7 \\
15 \\
32\end{array}$ & $\begin{array}{r}287.08 \\
276.74 \\
1031.62\end{array}$ & $\begin{array}{l}500 \\
190 \\
111\end{array}$ & $\begin{array}{l}2 \\
4 \\
6\end{array}$ & $\begin{array}{r}5 \\
8 \\
18\end{array}$ & $\begin{array}{r}48.34 \\
115.15 \\
958.11\end{array}$ \\
\hline & 0.5 & $\begin{array}{r}2 \\
5 \\
10\end{array}$ & $\begin{array}{l}2 \\
4 \\
6\end{array}$ & $\begin{array}{r}1776.36 \\
6575.61 \\
\mathrm{t}\end{array}$ & $\begin{array}{r}5 \\
10 \\
24\end{array}$ & $\begin{array}{l}210.40 \\
203.82 \\
391.21\end{array}$ & $\begin{array}{l}500 \\
190 \\
111\end{array}$ & $\begin{array}{l}2 \\
3 \\
4\end{array}$ & $\begin{array}{r}8 \\
20 \\
15\end{array}$ & $\begin{array}{r}143.98 \\
1197.45 \\
2507.41\end{array}$ \\
\hline & 0.8 & $\begin{array}{r}2 \\
5 \\
10\end{array}$ & $\begin{array}{l}2 \\
3 \\
4\end{array}$ & $\begin{array}{r}1425.14 \\
3621.65 \\
\mathrm{t}\end{array}$ & $\begin{array}{l}4 \\
8 \\
9\end{array}$ & $\begin{array}{l}172.08 \\
177.84 \\
180.13\end{array}$ & $\begin{array}{l}500 \\
190 \\
111\end{array}$ & $\begin{array}{l}2 \\
3 \\
4\end{array}$ & $\begin{array}{r}6 \\
10 \\
10\end{array}$ & $\begin{array}{r}35.75 \\
62.89 \\
104.66\end{array}$ \\
\hline 200 & 0.2 & $\begin{array}{r}2 \\
5 \\
10\end{array}$ & $\begin{array}{l}2 \\
4 \\
7\end{array}$ & $\begin{array}{l}t \\
t \\
t\end{array}$ & $\begin{array}{r}8 \\
12 \\
47\end{array}$ & $\begin{array}{r}656.69 \\
463.78 \\
1271.34\end{array}$ & $\begin{array}{l}500 \\
190 \\
111\end{array}$ & $\begin{array}{l}2 \\
4 \\
7\end{array}$ & $\begin{array}{r}7 \\
11 \\
15\end{array}$ & $\begin{array}{r}291.82 \\
1821.07 \\
3971.43\end{array}$ \\
\hline & 0.5 & $\begin{array}{r}2 \\
5 \\
10\end{array}$ & $\begin{array}{l}2 \\
4 \\
6\end{array}$ & $\begin{array}{l}t \\
t \\
t\end{array}$ & $\begin{array}{r}6 \\
16 \\
39\end{array}$ & $\begin{array}{r}419.86 \\
408.06 \\
2436.64\end{array}$ & $\begin{array}{l}500 \\
190 \\
111\end{array}$ & $\begin{array}{l}2 \\
4 \\
4\end{array}$ & $\begin{array}{r}9 \\
13 \\
18\end{array}$ & $\begin{array}{r}325.67 \\
1023.05 \\
2232.29\end{array}$ \\
\hline & 0.8 & $\begin{array}{r}2 \\
5 \\
10\end{array}$ & $\begin{array}{l}2 \\
3 \\
4\end{array}$ & $\begin{array}{l}t \\
t \\
t\end{array}$ & $\begin{array}{r}5 \\
13 \\
21\end{array}$ & $\begin{array}{l}332.53 \\
362.31 \\
455.65\end{array}$ & $\begin{array}{l}500 \\
190 \\
111\end{array}$ & $\begin{array}{l}2 \\
4 \\
4\end{array}$ & $\begin{array}{r}6 \\
16 \\
15\end{array}$ & $\begin{array}{r}188.61 \\
684.85 \\
1431.81\end{array}$ \\
\hline
\end{tabular}


et al. (2011) for around two thirds of the tested instances. Specially our approach is most efficient for instances with fewer hubs, which is rooted in the stress of our cut generation method on non-hub variables. Improvement of this method for larger number of hubs is the objective of future works.

\section{REFERENCES}

Alumur, S. and Kara, B. Y. (2008). Network hub location problems: The state of the art. European Journal of Operations Research, 190(1):1-21.

Benders, J. F. (1962). Partitioning procedures for solving mixed-variables programming problems. Numerische Mathematik, 4(1):238-252.

Campbell, J. F. (1994). Integer programming formulations of discrete hub location problems. European Journal of Operations Research, 72(2):387-405.

Campbell, J. F. (1996). Hub location and the p-hub median problem. Operations Research, 44(6):923-935.

Campbell, J. F., Ernst, A. T., and Krishnamoorthy, M. (2002). Hub location problems. Facility location: applications and theory, 1:373-407.

Campbell, J. F. and O'Kelly, M. E. (2012). Twenty-five years of hub location research. Transportation Science, 46(2):153-169.

Contreras, I., Cordeau, J.-F., and Laporte, G. (2011). Benders decomposition for large-scale uncapacitated hub location. Operations Research, 59(6):1477-1490.

de Camargo, R. S., Miranda, G. D., and Luna, H. (2008). Benders decomposition for the uncapacitated multiple allocation hub location problem. Computers \& Operations Research, 35(4):1047-1064.

Ernst, A. T. and Krishnamoorthy, M. (1996). Efficient algorithms for the uncapacitated single allocation p-hub median problem. Location science, 4(3):139-154.

Ernst, A. T. and Krishnamoorthy, M. (1999). Solution algorithms for the capacitated single allocation hub location problem. Annals of Operations Research, 86:141-159.

Farahani, R. Z., Hekmatfar, M., Arabani, A. B., and Nikbakhsh, E. (2013). Hub location problems: A review of models, classification, solution techniques, and applications. Computers and Industrial Engineering, 64(4):1096-1109.

Magnanti, T. L. and Wong, R. T. (1981). Accelerating Benders decomposition: Algorithmic enhancement and model selection criteria. Operations Research, 29(3):464-484.

Mayer, G. and Wagner, B. (2002). Hublocator: an exact solution method for the multiple allocation hub location problem. Computers \& Operations Research, 29(6):715-739.

Mokhtar, H., Krishnamoorthy, M., and Ernst, A. T. (2017a). The 2-allocation $p$-hub median problem and a modified benders decomposition method for solving hub location problems. submitted.

Mokhtar, H., Krishnamoorthy, M., and Ernst, A. T. (2017b). A modified benders method for the single- and multiple allocation $p$-hub median problems. submitted.

O'Kelly, M. E. (1986). The location of interacting hub facilities. Transportation Science, 20(2):92-106.

O'Kelly, M. E. (1987). A quadratic integer program for the location of interacting hub facilities. European Journal of Operations Research, 32(3):393-404. 